\title{
Comparing Perioperative Complications Between Laparoscopic and Robotic Radical Cystectomy for Bladder Cancer
}

\author{
Amandeep Arora, MCh, ${ }^{1,2}$ Felipe Pugliesi, MD, ${ }^{1,3}$ Ahmed S. Zugail, MD,, ${ }^{1,4}$ Marco Moschini, MD, PhD, 1,5 \\ Cristiano Pazeto, MD, ${ }^{1}$ Petr Macek, MD, Armando Stabile, MD, ${ }^{1,6}$ Camille Lanz, MD, Annick Mombet, MD, \\ Mostefa Bennamoun, MD, Rafael Sanchez-Salas, MD, ${ }^{1}$ and Xavier Cathelineau, MD ${ }^{1}$
}

\begin{abstract}
Background: Minimally invasive cystectomy is being increasingly performed, however, data comparing laparoscopic radical cystectomy (LRC) and robotic radical cystectomy (RRC) are scarce. We compared 30- and 90-day Clavien-Dindo Classification (CDC) complications between patients undergoing LRC and RRC at our center. Materials and Methods: We retrospectively evaluated 300 patients who underwent minimally invasive radical cystectomy from January 2007 to July 2019 and grouped them into LRC (112 patients) and RRC (188 patients). We compared the two groups for demographic variables, perioperative characteristics, and 30- and 90-day CDC overall, minor, and major complications. Multivariable logistic regression analysis was performed to identify variables that predict perioperative complications.

Results: The two groups were comparable for the duration of surgery (270 minutes in LRC vs 265 minutes in RRC) and rate of conversion to open surgery. The RRC cohort had a higher estimated blood loss (EBL) $(675 \mathrm{~mL}$ vs $500 \mathrm{~mL}, p=0.006)$, but the two groups had a comparable need for intraoperative transfusion. Patients undergoing RRC also had a shorter duration of hospital stay (13 days $v s 14$ days, $p<0.001$ ). There was no difference between the two groups for 30- and 90-day CDC overall, minor, and major complications. The incidence of rehospitalization within 30 days $(p=0.1)$ and surgical reintervention $(p=0.5)$ was also comparable between the two groups. On multivariable logistic regression analysis, approach to cystectomy (RRC vs LRC) was not a significant predictor of 30-day CDC overall and major complications.

Conclusion: LRC was associated with lesser EBL, whereas the hospital stay was shorter in patients undergoing RRC. The two approaches were comparable with each other for 30- and 90-day CDC overall, minor, and major complications. The choice between the two approaches should depend on availability and surgeon experience and preference, rather than any specific perioperative parameter.
\end{abstract}

Keywords: bladder cancer, radical cystectomy, complications, laparoscopic, robotics

\section{Introduction}

B LADDER CANCER (BCA) accounts for $\sim 7 \%$ of all malignancies and represents a huge oncologic and economic burden. ${ }^{1}$ Around $25 \%$ to $30 \%$ of these patients present with muscle invasive bladder cancer (MIBC). ${ }^{2}$ Radical cystectomy (RC) with bilateral pelvic lymph node dissection (PLND), after neoadjuvant chemotherapy (NAC), is the standard of care for nonmetastatic MIBC and recurrent high- risk nonmuscle invasive bladder cancer (NMIBC). ${ }^{3}$ Open radical cystectomy (ORC) has been the most commonly used approach with robust data available on feasibility, complications, and oncologic outcomes. However, there is significant perioperative morbidity associated with ORC with 30 - and 90-day overall Clavien-Dindo Classification (CDC) complication rates ranging from $30 \%$ to $60 \% .^{4-6}$

To circumvent some of the complications of this extensively extirpative surgery, minimally invasive RC was

\footnotetext{
${ }^{1}$ Department of Urology, Institut Mutualiste Montsouris, Paris, France.

${ }^{2}$ Department of Urology, Lokmanya Tilak Municipal Medical College and General Hospital, Mumbai, India.

${ }^{3}$ Division of Urology, Men's Health Centre, Hospital Brigadeiro, Sao Paulo, Brazil.

${ }_{5}^{4}$ Department of Urology, Faculty of Medicine in Rabigh, King Abdulaziz University, Jeddah, Saudi Arabia.

${ }^{5}$ Department of Urology, Luzerner Kantonsspital, Luzern, Switzerland.

${ }^{6}$ Department of Urology, Urological Research Institute, Vita-Salute University, San Raffaele Scientific Institute, Milan, Italy.

${ }^{7}$ Department of Medical Oncology, Institut Mutualiste Montsouris, Paris, France.
} 
described. However, laparoscopic radical cystectomy (LRC) with PLND is a technically challenging procedure and large series have mainly been reported from high-volume centers with experienced surgeons. ${ }^{7-10}$ Although robotic radical cystectomy (RRC) remains a technically demanding surgery, the robotic system offers much better ergonomics and a shorter learning curve than LRC. Consequently, there have been numerous series reported for RRC worldwide. ${ }^{1-13}$

Multiple systematic reviews have been published comparing ORC with LRC or RRC. ${ }^{14-18}$ Few reports directly compare the outcomes of LRC with RRC. ${ }^{19-22}$ At our highvolume oncology center, we offer LRC and RRC to our patients with $\mathrm{BCa}$. In this retrospective study, we sought to assess the perioperative CDC complications in our patients with LRC and RRC and determine whether either modality was better than the other. Secondary objectives included evaluating predictors of overall and major CDC complications, and analyzing the trend in performing LRC or RRC at our center over the past decade.

\section{Materials and Methods}

\section{Population}

The study was approved by the institutional review board We searched a prospectively maintained institutional RC registry for clinically nonmetastatic BCa. From January 2007 to July 2019, 305 patients underwent RC for nonmetastatic $\mathrm{BCa}$ at our institute. Of these, three patients underwent a simultaneous nephroureterectomy for a concurrent upper tract urothelial cancer and were excluded. We also excluded two patients who underwent open surgery. Of the remaining 300 patients, 112 and 188 patients underwent LRC and RRC, respectively, during the study period. Patients with urothelial cancers as well as those with histologic variants were included.

Data were collected for age, gender, height, weight, body mass index (BMI), American Society of Anesthesiologists (ASA) score, age-adjusted Charlson's Comorbidity Index (ACCI), and whether NAC was received (for patients undergoing $\mathrm{RC}$ for urothelial MIBC). We also noted the duration of surgery, estimated blood loss (EBL), need for intraoperative blood transfusion, duration of catheterization (in patients undergoing neobladder diversion), length of hospital stay, need for rehospitalization, surgical reintervention, histologic type of malignancy, pathologic $\mathrm{T}$ and $\mathrm{N}$ stages, carcinoma in situ, and margin positivity. We collected data for 30- and 90-day complications. All complications were graded as per the CDC system and grouped into minor (CDC I and II) and major (CDC $\geq$ III). ${ }^{23}$ Complications were also classified according to organ systems.

Male patients underwent either a radical cystoprostatectomy or a prostate-sparing cystectomy. ${ }^{24}$ Female patients underwent an anterior pelvic exenteration. All patients underwent a bilateral PLND. Up to 2011, patients underwent a "standard" PLND limited by the common iliac bifurcation superiorly, Cooper's ligament inferiorly, genitofemoral nerve laterally, and obturator nerve medially. From 2012 onward, an extended PLND was performed with its cranial limit being the aortic bifurcation.

Our techniques of LRC and RRC have been previously described. $^{8,25}$ From 2008 to 2011 , RRC was performed with the da Vinci S-HD robotic system (Intuitive Surgical, Inc.,
Mountain View, CA). Then in 2011, we changed for the da Vinci Si platform, which is the system that has been in use since then. The procedures were performed by one of seven surgeons. Every surgeon was fellowship trained and with sound experience in minimally invasive uro-oncologic procedures. Any conversion to open surgery was noted along with the reason for the same.

\section{Statistical analyses}

The unpaired " $t$ " test, Mann-Whitney $U$ test, and chisquare test were used to compare the statistical significance of differences in means, medians, and proportions, respectively. Univariable and multivariable logistic regression analyses tested the impact of perioperative variables in predicting the occurrence of overall and major CDC complications. Statistical significance was considered at $p<0.05$. Statistical analyses were performed using SPSS v.20.0 software (IBM SPSS Statistics, IBM Corporation, Armonk, NY).

\section{Results}

\section{Preoperative characteristics}

The two groups were similar in terms of patient age, gender, BMI, and the proportion of patients undergoing $\mathrm{RC}$ for high-risk NMIBC and MIBC (Table 1). Patients undergoing RRC had a higher ASA score $(p<0.001)$, higher ACCI $(p=0.016)$, and a higher proportion of use of NAC $(77 \% v s$ $51 \%, p<0.001)$ than those undergoing LRC.

\section{Intraoperative variables and pathologic findings}

Conversion to open surgery was required in five patients in each group (Table 2). The reasons for conversion included interbowel adhesions (four cases), common iliac vein injury (three cases), internal iliac artery injury (one case), rectal injury (one case), and fixed bladder mass with large lymph nodes (one case). There was no statistically significant difference between the two groups for the median duration of surgery (270 minutes in LRC vs 265 minutes in RRC), proportion of patients undergoing PLND, need for intraoperative blood transfusion ( $30 \%$ in LRC vs $42 \%$ in RRC, $p=0.052$ ), and the rate of margin positivity ( $8 \%$ in LRC and $7.4 \%$ in $\mathrm{RRC}, p=0.8)$. The RRC cohort was associated with a higher median EBL of $675 \mathrm{~mL}$ compared with $500 \mathrm{~mL}$ in the LRC cohort $(p=0.006)$.

\section{Postoperative course and complications}

The median duration of hospitalization in the RRC group was significantly shorter (13 days vs 14 days, $p<0.001$ ) (Table 3). Sixty percent of the patients had at least one complication at 30 days and the incidence of CDC overall complications was not significantly different in the two groups (57\% vs 62\%, $p=0.3)$.

When categorized as CDC minor (I, II) and major ( $\geq \mathrm{III})$ complications, $19.5 \%$ of RRC patients had a major complication compared with $18 \%$ in the LRC group $(p=0.6)$. Four patients (one LRC and three RRC) died within 30 days of the RC: two of them because of pulmonary embolism, while the other two as a result of urosepsis. There were 18 additional complications between days 30 and 90 and the difference between the two groups for 90-day CDC overall and major 
Table 1. Preoperative Characteristics of 300 Patients Who Underwent Minimally Invasive Radical Cystectomy with Pelvic Lymph Node Dissection from January 2007 to July 2019

\begin{tabular}{|c|c|c|c|c|}
\hline Variable & $\begin{array}{l}\text { Overall population } \\
(\mathrm{n}=300 ; 100 \%)\end{array}$ & $\begin{array}{c}L R C \\
(\mathrm{n}=112 ; 37 \%)\end{array}$ & $\begin{array}{c}R R C \\
(\mathrm{n}=188 ; 63 \%)\end{array}$ & $\mathrm{p}$ \\
\hline $\begin{array}{l}\text { Age (years) } \\
\text { Median (IQR) }\end{array}$ & $67(62-74)$ & $66(61-74)$ & $68(63-74)$ & 0.1 \\
\hline $\begin{array}{l}\text { Gender, } n(\%) \\
\text { Male } \\
\text { Female }\end{array}$ & $\begin{array}{r}260(87) \\
40(13)\end{array}$ & $\begin{array}{l}92(82) \\
20(18)\end{array}$ & $\begin{array}{r}168(89.5) \\
20(10.5)\end{array}$ & 0.07 \\
\hline $\begin{array}{r}\mathrm{BMI}\left(\mathrm{kg} / \mathrm{m}^{2}\right) \\
\quad \text { Mean } \pm \mathrm{SD}\end{array}$ & $26.09 \pm 4.32$ & $26.32 \pm 4.87$ & $26.97 \pm 4.01$ & 0.51 \\
\hline $\begin{array}{l}\text { History of smoking, } \\
\text { Nonsmoker } \\
\text { Current } \\
\text { Past }\end{array}$ & $\begin{aligned} & 53(17.6) \\
& 114(38) \\
& 93(31)\end{aligned}$ & $\begin{array}{l}16(14) \\
36(32) \\
32(28.5)\end{array}$ & $\begin{array}{l}37(19.6) \\
78(41.4) \\
61(32.4)\end{array}$ & 0.8 \\
\hline $\begin{array}{l}\text { ASA score, } n(\%) \\
\text { I } \\
\text { II } \\
\text { III }\end{array}$ & $\begin{array}{r}49(16) \\
187(62) \\
42(14)\end{array}$ & 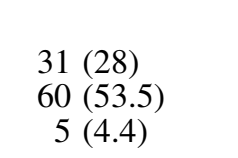 & $\begin{array}{r}18(9.5) \\
127(67.5) \\
37(19.6)\end{array}$ & $<0.001$ \\
\hline $\begin{array}{l}\text { ACCI }(n) \\
2-4 \\
5-6 \\
>6\end{array}$ & $\begin{array}{l}121 \\
109 \\
55\end{array}$ & $\begin{array}{l}51 \\
37 \\
11\end{array}$ & $\begin{array}{l}70 \\
72 \\
44\end{array}$ & 0.02 \\
\hline $\begin{array}{l}\text { Clinical stage of uro } \\
\text { High risk NMIBC } \\
\text { MIBC }\end{array}$ & $\begin{array}{r}a, n(\%) \\
34(13) \\
244(87)\end{array}$ & $\begin{aligned} 8 & (8) \\
94 & (92)\end{aligned}$ & $\begin{array}{r}26(15) \\
150(85)\end{array}$ & 0.08 \\
\hline $\begin{array}{l}\text { NAC for urothelial } \\
\text { Yes } \\
\text { No }\end{array}$ & 7) $\begin{array}{r}163(67) \\
81(33)\end{array}$ & $\begin{array}{l}48(51) \\
46(49)\end{array}$ & $\begin{array}{r}115(77) \\
35(23)\end{array}$ & $<0.001$ \\
\hline
\end{tabular}

The bold values signify that the $p$ value for that variable is significant.

ACCI $=$ age-adjusted Charlson's comorbidity index; ASA = American Society of Anesthesiologists; $\mathrm{BCa}=$ bladder cancer; $\mathrm{BMI}=$ body mass index; IQR = interquartile range; $\mathrm{LRC}=$ laparoscopic radical cystectomy; $\mathrm{MIBC}=$ muscle invasive bladder cancer; $\mathrm{NAC}=$ neoadjuvant chemotherapy; $\mathrm{NMIBC}=$ nonmuscle invasive bladder cancer; $\mathrm{RRC}=$ robotic radical cystectomy; $\mathrm{SD}=$ standard deviation .

complications continued to remain insignificant. Five patients in the LRC group had a complication between 30 and 90 days: urinary tract infection (UTI) (two patients), urinary leak (one patient), pelvic abscess (one patient), and anemia requiring transfusion (one patient). For the RRC group, 13 patients had a complication between days 30 and 90: UTI (4 patients), anemia (4 patients), ureteroenteral anastomotic stricture ( 2 patients), neobladder fistula (1 patient), neobladder retention (1 patient), neobladder-urethral anastomotic stricture (1 patient).

With regard to rehospitalization within 30 days and surgical reintervention, there was no significant difference between the two groups. In the LRC group, 17 (15.1\%) patients required a readmission within 30 days, reasons being UTI requiring intravenous antibiotics (18 patients), urinary leak (2 patients), anemia requiring blood transfusion (2 patients), ureteroenteral anastomotic stricture (1 patient), and intestinal obstruction (1 patient). Reasons for 30-day readmission in the RRC group (43 patients, 22.8\%) included UTI (25 patients), urinary leak (5 patients), requirement of blood transfusion (7 patients), ureteroenteral anastomotic stricture (2 patients), neobladder retention (1 patient), subacute intestinal obstruction (1 patient), pulmonary embolism (1 patient), and dyspnoea because of pulmonary metastasis (1 patient). No difference was noted between the two groups with regard to organ-specific complications (Table 4). The surgical reinterventions are summarized in Table 5.

\section{Predictors of complications}

On univariable analysis, ASA score (odds ratio [OR]: 2.90, confidence interval [CI]: 1.17-7.19, $p=0.02)$, neobladder $v s$ ileal conduit diversion (OR: 1.68, CI: 1.01-2.82, $p=0.04$ ), and EBL (OR: 1.001, CI: 1.001-1.002, $p<0.001)$ were found to significantly predict the occurrence of 30-day overall CDC complications (Table 6). On multivariable analysis, ASA score (OR: 2.82, CI: 1.08-7.38, $p=0.03$ ) and EBL (OR: 1.002, CI: $1.001-1.002, p<0.001)$ retained their significance to predict overall CDC complications. None of the factors were found to be significantly associated with CDC major complications. Surgical approach (RRC vs LRC) was not found to be significantly associated with overall CDC (OR: 1.56, CI: 0.95-2.58, $p=0.07$ ) or major CDC complications (OR: 0.97, CI: $0.53-1.77, p=0.9$ ) on univariable analysis.

\section{Trends in surgical approach and complications}

We began performing RRC in 2008 and its use has increased over the years to $50 \%$ of all cystectomies in 2011 and then to $100 \%$ of cystectomies since 2015 (Fig. 1). The trends of overall, minor, and major CDC complications are shown in Figure 2. The fluctuations in all three trend lines are not statistically significant. Combining the observations of these two figures, we can conclude that although our approach to $\mathrm{RC}$ has shifted over the years from LRC to RRC, the 
Table 2. Intraoperative Characteristics and Histopathologic Findings of 300 Patients Who Underwent Minimally Invasive Radical Cystectomy from January 2007 to July 2019

\begin{tabular}{|c|c|c|c|c|}
\hline Variable & $\begin{array}{l}\text { Overall population } \\
(\mathrm{n}=300 ; 100 \%)\end{array}$ & $\begin{array}{c}L R C \\
(\mathrm{n}=112 ; 37.33 \%)\end{array}$ & $\begin{array}{c}R R C \\
(\mathrm{n}=188 ; 62.66 \%)\end{array}$ & $\mathrm{p}$ \\
\hline \multicolumn{5}{|l|}{ Surgery in men, $n(\%)$} \\
\hline Radical cystoprostatectomy & $239(79.5)$ & $81(72.3)$ & $158(84)$ & \multirow[t]{2}{*}{0.08} \\
\hline Prostate sparing cystectomy & $21(7)$ & $11(9.8)$ & $10(5.3)$ & \\
\hline Conversion to open surgery, $n(\%)$ & $10(3.3)$ & $5(4.4)$ & $5(2.6)$ & 0.2 \\
\hline \multicolumn{5}{|l|}{ Diversion, $n(\%)$} \\
\hline Ileal conduit & $179(60)$ & $69(61.6)$ & $110(58.5)$ & \multirow[t]{2}{*}{0.5} \\
\hline Neobladder & $121(40)$ & $43(38.4)$ & $78(41.4)$ & \\
\hline Duration of surgery (minutes) & 270 & 270 & 265 & \multirow[t]{2}{*}{0.6} \\
\hline Median (IQR) & $(220-300)$ & $(240-300)$ & $(220-300)$ & \\
\hline $\mathrm{EBL}(\mathrm{mL})$ & 600 & 500 & 675 & \multirow[t]{2}{*}{0.006} \\
\hline Median (IQR) & $(400-900)$ & $(400-800)$ & $(450-950)$ & \\
\hline Intraoperative blood transfusion, $n(\%)$ & $113(37.6)$ & $34(30)$ & $79(42)$ & 0.052 \\
\hline \multicolumn{5}{|l|}{ Pathologic T stage, $n(\%)$} \\
\hline pT0 & $62(20.6)$ & $18(16)$ & $44(23.4)$ & \multirow[t]{4}{*}{0.4} \\
\hline pTa-Tis-T1 & $57(19)$ & $20(17.8)$ & $37(19.6)$ & \\
\hline $\mathrm{pT} 2$ & $59(19.6)$ & $25(22.3)$ & $34(18)$ & \\
\hline pT3-T4 & $121(40.3)$ & $48(42.9)$ & $73(38.8)$ & \\
\hline Pelvic lymph node dissection, $n(\%)$ & $273(91)$ & $98(87.5)$ & $175(93)$ & 0.1 \\
\hline \multicolumn{5}{|l|}{ Pathologic N stage, $n(\%)$} \\
\hline $\mathrm{pN} 0$ & $208(69)$ & $73(65)$ & $135(72)$ & \multirow[t]{4}{*}{0.6} \\
\hline $\mathrm{pN} 1$ & $22(7)$ & $9(8)$ & $13(7)$ & \\
\hline $\mathrm{pN} 2$ & $38(13)$ & $13(11.6)$ & $25(13)$ & \\
\hline $\mathrm{pN} 3$ & $5(1.6)$ & $3(2.6)$ & $2(1)$ & \\
\hline Concomitant CIS, $n(\%)$ & $81(27)$ & $31(27.6)$ & $50(26.5)$ & 0.4 \\
\hline Margin positivity, $n(\%)$ & $23(7.6)$ & $9(8)$ & $14(7.4)$ & 0.8 \\
\hline \multicolumn{5}{|l|}{ Histology, $n(\%)$} \\
\hline Urothelial & $270(90)$ & $101(90)$ & $169(90)$ & \multirow[t]{3}{*}{0.2} \\
\hline Variant & $8(2.6)$ & $1(0.9)$ & $7(3.7)$ & \\
\hline Nonurothelial & $22(7.3)$ & $10(9)$ & $12(6)$ & \\
\hline
\end{tabular}

The bold value signifies that the $p$ value for that variable is significant.

$\mathrm{CIS}=$ carcinoma in situ; $\mathrm{EBL}=$ estimated blood loss.

Table 3. Perioperative Complications and Postoperative Course of 300 Patients Who Underwent Minimally Invasive Radical Cystectomy from January 2007 to July 2019

\begin{tabular}{|c|c|c|c|c|}
\hline Variable & $\begin{array}{l}\text { Overall population } \\
(\mathrm{n}=300 ; 100 \%)\end{array}$ & $\begin{array}{c}L R C(\mathrm{n}=112 ; \\
37.33 \%)\end{array}$ & $\begin{array}{l}R R C(\mathrm{n}=188 ; \\
\quad 62.66 \%)\end{array}$ & $\mathrm{p}$ \\
\hline $\begin{array}{l}\text { Duration of catheterization for patients } \\
\text { with neobladder (days) } \\
\text { Median (IQR) }\end{array}$ & $12(10-14)$ & $12(10-14)$ & $12(10-14)$ & 0.6 \\
\hline $\begin{array}{l}\text { Duration of hospitalization (days) } \\
\text { Median (IQR) }\end{array}$ & $13(12-16)$ & $14(13-17)$ & $13(12-15)$ & $<0.001$ \\
\hline \multicolumn{5}{|l|}{ 30-day CDC complications, $n(\%)$} \\
\hline Overall & $181(60)$ & $64(57)$ & $117(62)$ & 0.3 \\
\hline Minor (Grade I, II) & $124(42)$ & $44(39)$ & $80(42.5)$ & 0.5 \\
\hline Major (Grade $\geq$ III) & 57 (19) & $20(18)$ & $37(19.5)$ & 0.6 \\
\hline \multicolumn{5}{|l|}{ 90-day CDC complications, $n(\%)$} \\
\hline Overall & $199(66.3)$ & $69(61.6)$ & $130(69)$ & 0.1 \\
\hline Minor (Grade I, II) & $133(44.3)$ & $46(41)$ & $87(46)$ & 0.5 \\
\hline Major (Grade $\geq$ III) & $66(22)$ & $23(20.5)$ & $43(23)$ & 0.6 \\
\hline Surgical reintervention, $n(\%)$ & $51(17)$ & $17(15.1)$ & $34(18)$ & 0.5 \\
\hline Early hospitalization (<30 days), $n(\%)$ & $60(20)$ & $17(15.1)$ & $43(22.87)$ & 0.1 \\
\hline
\end{tabular}

The bold value signifies that the $p$ value for that variable is significant.

$\mathrm{CDC}=$ Clavien-Dindo Classification. 
TABle 4. ThiRTy-Day COMPlications AS PER the Clavien-Dindo Classification and as PER

ORgan SySTEMS IN 300 PATIENTS Who UNDERWENT Minimally InVASIVE Radical CySTECTOMY FROM JANUARY 2007 TO JULY 2019.

\begin{tabular}{|c|c|c|c|}
\hline & $\begin{array}{c}L R C \\
(\mathrm{n}=112 ; \\
37 \%)\end{array}$ & $\begin{array}{c}R R C \\
(\mathrm{n}=188 ; \\
63 \%)\end{array}$ & $\mathrm{p}$ \\
\hline \multicolumn{4}{|c|}{ CDC complication grade } \\
\hline Grade 0 & 42 & 52 & - \\
\hline Grade I & 5 & 20 & \\
\hline Grade II & 39 & 60 & \\
\hline Grade IIIa & 1 & 9 & \\
\hline Grade IIIb & 8 & 19 & \\
\hline Grade IVa & 10 & 6 & \\
\hline Grade IVb & 0 & 0 & \\
\hline Grade V & 1 & 3 & \\
\hline $\begin{array}{l}\text { Wound infection/ } \\
\text { dehiscence }\end{array}$ & 6 & 4 & 0.1 \\
\hline \multicolumn{4}{|l|}{ Urinary } \\
\hline (1) Overall & $32(28.5 \%)$ & $63(33.5 \%)$ & 0.3 \\
\hline $\begin{array}{l}\text { (2) Urinary tract } \\
\text { infection }\end{array}$ & $22(19.6 \%)$ & $42(22.3 \%)$ & \\
\hline (3) Urinary fistula & 6 & 10 & \\
\hline $\begin{array}{l}\text { (4) Neobladder } \\
\text { retention }\end{array}$ & 2 & 5 & \\
\hline $\begin{array}{l}\text { (5) Renal } \\
\text { insufficiency }\end{array}$ & 1 & 4 & \\
\hline $\begin{array}{l}\text { (6) Ureteral } \\
\text { anastomosis } \\
\text { stricture }\end{array}$ & 2 & 4 & \\
\hline Pulmonary & 3 & 6 & 1.0 \\
\hline Cardiac & 5 & 2 & 0.1 \\
\hline Gastrointestinal & $16(14 \%)$ & $20(10.6 \%)$ & 0.3 \\
\hline Transfusion & $19(17 \%)$ & $34(18 \%)$ & 0.8 \\
\hline Lymphocele & 3 & 0 & 0.051 \\
\hline Dyselectrolytemia & 2 & 4 & 1.0 \\
\hline Obturator palsy & 1 & 2 & 1.0 \\
\hline Pulmonary embolism & 2 & 3 & 1.0 \\
\hline
\end{tabular}

incidence of overall, minor, and major CDC complications has remained fairly similar.

\section{Discussion}

RC with bilateral PLND has traditionally been performed through the open approach. However, it is associated with significant perioperative morbidity. ${ }^{4-6}$ The technical challenge of performing an LRC meant that large series have mainly been reported from high-volume centers with experienced surgeons. $^{7-10}$ This technical difficulty and the concurrent availability of the da Vinci ${ }^{\circledR}$ Surgical System since 2001 resulted in failure of widespread adoption of LRC. As a result of better ergonomics and a shorter learning curve compared with $\mathrm{LRC}$, there have been numerous series reported for RRC worldwide. $^{11-13,26}$

Multiple systematic reviews have been published comparing ORC with LRC or RRC. ${ }^{14-18}$ The general consensus is that RRC/LRC result in a similar complication profile as ORC but are associated with lesser blood loss and a shorter hospital stay. Although the established benefit of minimally invasive $\mathrm{RC}$ over ORC is modest, recent trials such as CORAL and BOLERO have shown poor patient accrual, with patients
Table 5. Surgical Reinterventions Within 30 Days FOR 300 Patients Who UnderWENT Minimally Invasive Radical CySTECTOMY FROM JANUARY 2007 TO JULY 2019

\begin{tabular}{lcc}
\hline $\begin{array}{l}\text { Description } \\
(\mathrm{n}=112)\end{array}$ & $\begin{array}{c}R R C \\
(\mathrm{n}=188)\end{array}$ \\
\hline $\begin{array}{l}\text { Abdominal wall suturing } \\
\quad \text { for wound dehiscence }\end{array}$ & 3 & 5 \\
$\begin{array}{l}\text { Adhesiolysis for bowel } \\
\quad \text { obstruction }\end{array}$ & 4 & 4 \\
$\begin{array}{l}\text { Neobladder fistula repair } \\
\text { Pelvic abscess drainage }\end{array}$ & 3 & 5 \\
$\begin{array}{l}\text { Ureteral reimplantation for } \\
\text { stenosis/leak }\end{array}$ & 2 & 3 \\
$\begin{array}{l}\text { Bilateral nephrostomy insertion } \\
\text { Ureterosigmoidostomy }\end{array}$ & 1 & 6 \\
$\begin{array}{l}\text { Cystoscope-guided catheterization } \\
\text { for neobladder retention }\end{array}$ & 1 & 3 \\
$\begin{array}{l}\text { Laparotomy for bowel leak } \\
\text { Cystoscopic incision for } \\
\quad \text { neobladder-urethral }\end{array}$ & 1 & 0 \\
$\quad$ anastomotic narrowing & 1 & 3 \\
$\quad$ Total & 0 & 4 \\
\hline
\end{tabular}

preferring LRC or RRC over ORC and thus preventing randomization. $^{21,27}$ The RAZOR trial was the only recent trial with large patient accrual (174 ORC vs $176 \mathrm{RRC})$, but it was performed in $>15$ high-volume centers in the United States. ${ }^{28}$ We believe that minimally invasive $\mathrm{RC}$ would have more widespread adoption in the future and the complication rate will only get better with increased surgeon experience.

Although most of the recent single-center reports are about experience with RRC, lack of widespread availability and increased cost with the robotic system means that LRC remains an important means of offering minimally invasive $\mathrm{RC}$. There is paucity of data for direct comparison of perioperative outcomes between LRC and RRC. At our highvolume center, we have been performing LRC since 2001 and RRC since 2008. To the best of our knowledge, this study represents the largest series in the Western world comparing complications between LRC and RRC.

We studied a total of 300 patients who underwent minimally invasive RC. Most of the previous retrospective reports comparing LRC or RRC with ORC were criticized for selection bias that might have inflated the difference in complications between ORC and LRC/RRC. During our study period, all patients with $\mathrm{BCa}$ underwent either LRC or RRC (two patients who underwent upfront ORC were excluded). This eliminated any bias regarding selection of younger and healthier patients with low disease burden for minimally invasive RC. Also, over the past few years, we have been performing all cystectomies by the robotic approach that has further eliminated selection bias (at least in the past 4 years) while comparing outcomes between LRC and RRC.

In our study, there was no significant difference between the two cohorts with regard to age, gender, and BMI. However, the patients in the RRC cohort had a higher ASA score and ACCI than the LRC group. This could probably just be a result of patients with more comorbidities presenting to us in the latter half of the study period when the number of RRC procedures exceeded LRCs. Similarly, the RRC group had a 
Table 6. Predictors of 30-Day Clavien-Dindo Classification Overall and Major Complications Using Univariable and Multivariable Logistic Regression

Predictors of 30-day CDC overall complications

\begin{tabular}{|c|c|c|c|c|}
\hline \multirow[b]{2}{*}{ Variable } & \multicolumn{2}{|c|}{ Univariable analysis } & \multicolumn{2}{|c|}{ Multivariable analysis } \\
\hline & OR $(95 \% C I)$ & $\mathrm{p}$ & OR $(95 \% C I)$ & $\mathrm{p}$ \\
\hline Age, years & $0.984(0.956-1.012)$ & 0.2 & $0.982(0.946-1.019)$ & 0.3 \\
\hline ASA III $v s$ ASA I, II & $2.906(1.174-7.190)$ & 0.02 & $2.824(1.080-7.380)$ & 0.03 \\
\hline NAC (yes vs no) & $1.038(0.582-1.851)$ & 0.8 & $0.980(0.573-1.679)$ & 0.9 \\
\hline RRC vs LRC & $1.569(0.953-2.583)$ & 0.07 & $1.193(0.674-2.111)$ & 0.5 \\
\hline Neobladder $v s$ ileal conduit & $1.688(1.010-2.821)$ & 0.046 & $1.618(0.850-3.079)$ & 0.1 \\
\hline EBL & $1.001(1.000-1.002)$ & $<0.001$ & $1.002(1.001-1.002)$ & $<0.001$ \\
\hline pT3-4 vs pT0-2 & $0.786(0.480-1.288)$ & 0.3 & $1.063(0.597-1.892)$ & 0.8 \\
\hline
\end{tabular}

Predictors of 30-day CDC major complications

\begin{tabular}{lcccc}
\hline \multirow{2}{*}{ Variable } & \multicolumn{2}{c}{ Univariable analysis } & & Multivariable analysis \\
\cline { 2 - 3 } Age, years & OR $(95 \%$ CI $)$ & $\mathrm{p}$ & OR $(95 \%$ CI $)$ \\
ASA III vs ASA I, II & $0.973(0.941-1.006)$ & 0.1 & $0.983(0.945-1.022)$ \\
NAC (yes vs no) & $0.996(0.471-2.108)$ & 0.9 & $1.152(0.506-2.621)$ \\
RRC vs LRC & $1.411(0.578-2.252)$ & 0.7 & $0.848(0.460-1.563)$ \\
Neobladder vs ileal conduit & $0.972(0.532-1.774)$ & 0.9 & $0.872(0.451-1.686)$ \\
EBL & $1.586(0.891-2.822)$ & 0.1 & $1.205(0.609-2.384)$ & 0.3 \\
pT3-4 vs pT0-2 & $1.000(0.999-1.000)$ & 0.8 & $1.000(0.999-1.001)$ & 0.5 \\
\hline
\end{tabular}

The bold values signify that the $p$ value for that variable is significant.

$\mathrm{CI}=$ confidence interval; $\mathrm{OR}=$ odds ratio.

higher percentage of patients who had received NAC for urothelial MIBC. This can be explained by the fact that the use of NAC at our institute has grown substantially over time ( $\sim 85 \%$ of eligible patients presently).

Duration of surgery was comparable in the two cohorts (median of 265 minutes in LRC and 270 minutes in RRC). It is noteworthy that the operating time in RRC included the time required for docking of the robot. The median EBL in our RRC cohort was $675 \mathrm{~mL}$, whereas that in the LRC group was $500 \mathrm{~mL}$, with the difference being statistically significant. However, this difference does not seem to be clinically significant as it did not translate to a significantly higher rate of intraoperative blood transfusion in the RRC group. Similar findings were reported by $\mathrm{Su}$ et al. in their recent retrospective comparison of LRC with RRC. ${ }^{22}$ The CORAL trial is the only prospective study comparing LRC with RRC and it had re- ported a significantly longer operating time and similar EBL for RRC compared with LRC, but these results have to be interpreted in light of the small sample size in that study (20 in each arm). ${ }^{21}$ The median length of hospital stay in the RRC group was 1 day shorter than that in the LRC group (13 days $v s$ 14 days), and although this difference was found to be statistically significant, its clinical implication is debatable.

Our results show no difference between the two groups with regard to CDC overall, minor, and major complications at both 30- and 90-day interval postsurgery. In addition, on multivariable logistic regression analysis, the approach to cystectomy (RRC vs LRC) was not found to be a significant predictor of 30-day CDC overall and major complications. The CORAL trial also did not find a significant difference but the number of complications was too small to draw a conclusion. ${ }^{21}$ Khan and colleagues reported a higher complication
FIG. 1. Trends of surgical approach to radical cystectomy at our institute over time.

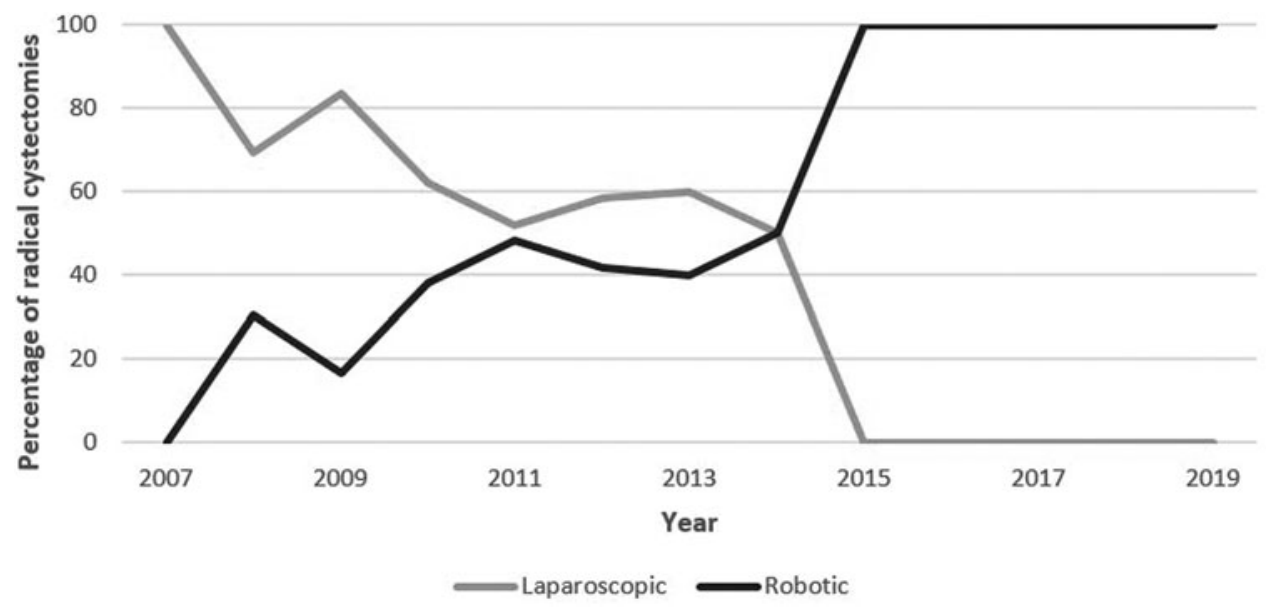




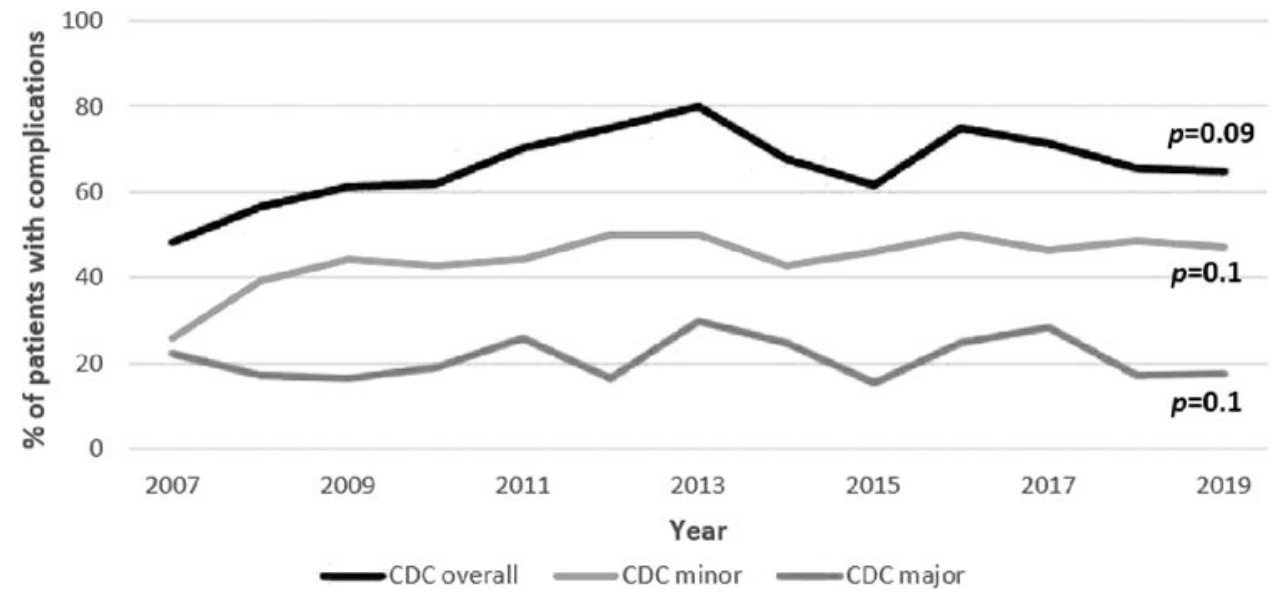

FIG. 2. Trends of CDC overall, minor (Grade I, II), and major (Grade $\geq \mathrm{III})$ complications. $\mathrm{CDC}=$ ClavienDindo Classification. rate in LRC, especially left ureteroenteral anastomotic stricture $(13.7 \%)$, which they attributed to inadequate left ureteral mobilization. ${ }^{20}$ We experienced a ureteral anastomotic stricture in $\sim 2 \%$ of the cases in each group. This low ureteral anastomotic stricture rate could be a reflection of the fact that we use the Wallace technique for the anastomosis.

Even while comparing for organ-specific complications, no significant differences were seen between the LRC and RRC groups. The most common complications were infectious postoperative blood transfusion and gastrointestinal complications. These findings are comparable with those reported previously in the literature. ${ }^{4,13,20}$ Logistic regression analysis identified ASA score (III $v s$ I, II) and EBL as independent predictors of 30-day overall CDC complications. Multiple prior reports have identified high ASA score to be a predictor of perioperative morbidity, although some of these were analyzing complications in ORC. ${ }^{13,29,30}$ None of the factors in the logistic regression model were found to be significant predictors of 30-day major CDC complications.

At our institute, the use of robotic approach for cystectomy has steadily increased over the years and now all patients planned for a minimally invasive cystectomy undergo an RRC. In contrast, the use of LRC has gradually declined. Despite this shift in the surgical approach, there has been no significant change in the incidence of complications. This reiterates the finding of surgical approach not being an independent predictor for complications. The shift from LRC to RRC at our center could be because of increasing experience of the surgeons in using the robotic platform, a shorter learning curve with the robotic approach, and the ergonomic ease offered by the robotic system. Also, we did not find the type of robotic platform (da Vinci S-HD or da Vinci Si) to have an impact on our PLND or the neobladder-urethral anastomosis.

We acknowledge certain limitations of our study. First, data were collected retrospectively and thus the results are subject to selection bias. This has been automatically avoided in the past 4 years when we have been performing only RRC for BCa. Second, the results do not apply to patients undergoing an intracorporeal reconstruction for urinary diversion. Third, ours is a high-volume uro-oncology center with vastly experienced surgeons, and thus our outcomes are indicative of this setting and may not be applicable to centers not routinely performing minimally invasive RC. Also, being a retrospective study, there may be an element of bias in the reporting of complications. Despite the mentioned limitations, our series is one of the largest till date to compare perioperative complications between LRC and RRC. Except for higher EBL in LRC and a shorter hospital stay with RRC (the magnitudes of these differences seem clinically insignificant), our results do not demonstrate any difference in conversion to open surgery, incidence of positive surgical margins, and perioperative complications between the two cohorts. Thus, choosing between the two approaches would depend on availability of the robotic system, surgeon experience, and preference; and patients need to be counseled about comparable outcomes.

\section{Conclusions}

LRC and RRC are both feasible approaches for minimally invasive RC and PLND. LRC was associated with lesser EBL while the hospital stay was shorter in patients undergoing RRC. The two approaches were comparable to each other for 30- and 90-day CDC overall, minor, and major complications. For a surgeon, the choice between the two approaches would depend on availability and personal experience and preference, rather than any specific perioperative parameter.

\section{Author Disclosure Statement}

No competing financial interests exist.

\section{Funding Information}

No funding was provided for this article.

\section{References}

1. Antoni S, Ferlay J, Soerjomataram I, Znaor A, Jemal A, Bray F. Bladder cancer incidence and mortality: A global overview and recent trends. Eur Urol 2017;71:96-108.

2. Cumberbatch MGK, Noon AP. Epidemiology, aetiology and screening of bladder cancer. Vol. 8, Translational Andrology and Urology. Transl Androl Urol 2019;8:5-11.

3. Alfred Witjes J, Lebret T, Compérat EM, et al. Updated 2016 EAU Guidelines on Muscle-invasive and Metastatic Bladder Cancer. Eur Urol 2017;71:462-475.

4. Shabsigh A, Korets R, Vora KC, et al. Defining early morbidity of radical cystectomy for patients with bladder cancer using a standardized reporting methodology. Eur Urol 2009;55:164-176.

5. Novara G, De Marco V, Aragona M, et al. Complications and mortality after radical cystectomy for bladder transitional cell cancer. J Urol 2009;182:914-921. 
6. Moschini M, Simone G, Stenzl A, Gill IS, Catto J. Critical review of outcomes from radical cystectomy: Can complications from radical cystectomy be reduced by surgical volume and robotic surgery? Eur Urol Focus 2016;2: 19-29.

7. Huang $\mathrm{J}$, Lin $\mathrm{T}$, Liu $\mathrm{H}$, et al. Laparoscopic radical cystectomy with orthotopic ileal neobladder for bladder cancer: Oncologic results of 171 cases with a median 3-year follow-up. Eur Urol 2010;58:442-449.

8. Cathelineau X, Arroyo C, Rozet F, Barret E, Vallancien G. Laparoscopic assisted radical cystectomy: The Montsouris experience after 84 cases. Eur Urol 2005;47:780-784.

9. Haber GP, Gill IS. Laparoscopic radical cystectomy for cancer: Oncological outcomes at up to 5 years. BJU Int 2007;100:137-142.

10. Hemal AK, Kolla SB, Wadhwa P, Dogra PN, Gupta NP. Laparoscopic radical cystectomy and extracorporeal urinary diversion: A single center experience of 48 cases with three years of follow-up. Urology 2008;71:41-46.

11. Pruthi RS, Nielsen ME, Nix J, Smith A, Schultz H, Wallen EM. Robotic radical cystectomy for bladder cancer: Surgical and pathological outcomes in 100 consecutive cases. J Urol 2010;183:510-515.

12. Collins JW, Tyritzis S, Nyberg T, et al. Robot-assisted radical cystectomy: Description of an evolved approach to radical cystectomy. Eur Urol 2013;64:654-663.

13. Ng CK, Kauffman EC, Lee MM, et al. A comparison of postoperative complications in open versus robotic cystectomy. Eur Urol 2010;57:274-282.

14. Lauridsen SV, Tønnesen H, Jensen BT, Neuner B, Thind P, Thomsen T. Complications and health-related quality of life after robot-assisted versus open radical cystectomy: A systematic review and meta-analysis of four RCTs. Syst Rev 2017;6:150.

15. Tan WS, Khetrapal P, Tan WP, Rodney S, Chau M, Kelly JD. Robotic assisted radical cystectomy with extracorporeal urinary diversion does not show a benefit over open radical cystectomy: A systematic review and meta-analysis of randomised controlled trials. PLoS One 2016;11:e0166221.

16. Rai BP, Bondad J, Vasdev N, et al. Robotic versus open radical cystectomy for bladder cancer in adults. BJU Int 2019;4:CD011903.

17. Ilic D, Evans SM, Allan CA, Jung JH, Murphy D, Frydenberg M. Laparoscopic and robotic-assisted versus open radical prostatectomy for the treatment of localised prostate cancer. Cochrane Database Syst Rev 2017;9:CD009625.

18. Tang K, Li H, Xia D, Hu Z, Zhuang Q, Liu J, Xu H, Ye Z. Laparoscopic versus open radical cystectomy in bladder cancer: A systematic review and meta-analysis of comparative studies. PLoS One 2014;9:e95667.

19. Abraham JBA, Young JL, Box GN, Lee HJ, Deane LA, Ornstein DK. Comparative analysis of laparoscopic and robot-assisted radical cystectomy with ileal conduit urinary diversion. J Endourol 2007;21:1473-1480.

20. Khan MS, Challacombe B, Elhage O, et al. A dual-centre, cohort comparison of open, laparoscopic and robotic-assisted radical cystectomy. Int J Clin Pract 2012;66:656-662.

21. Khan MS, Gan C, Ahmed K, et al. A single-centre early phase randomised controlled three-arm trial of open, Robotic, and Laparoscopic Radical Cystectomy (CORAL). Eur Urol 2016;69:613-621.

22. Su S, Gu L, Ma X, et al. Comparison of laparoscopic and robot-assisted radical cystectomy for bladder cancer: Perioperative and oncologic outcomes. Clin Genitourin Cancer 2019;17:e1048-e1053.
23. Dindo D, Demartines N, Clavien PA. Classification of surgical complications: A new proposal with evaluation in a cohort of 6336 patients and results of a survey. Ann Surg 2004;240:205-213.

24. Saad M, Moschini M, Stabile A, et al. Long-term functional and oncological outcomes of nerve-sparing and prostate capsule-sparing cystectomy: A single-centre experience. BJU Int 2020;125:253-259.

25. Kasraeian A, Barret E, Cathelineau X, et al. Robot-assisted laparoscopic cystoprostatectomy with extended pelvic lymphadenectomy, extracorporeal enterocystoplasty, and intracorporeal enterourethral anastomosis: Initial montsouris experience*. J Endourol 2010;24:409-413.

26. Soria F, Moschini M, D'andrea D, et al. Comparative effectiveness in perioperative outcomes of robotic versus open radical cystectomy: Results from a multicenter contemporary retrospective cohort study. Eur Urol Focus 2018; S2405-4569(18)30334-1.

27. Harrop E, Kelly J, Griffiths G, Casbard A, Nelson A. Why do patients decline surgical trials? Findings from a qualitative interview study embedded in the Cancer Research UK BOLERO trial (Bladder cancer: Open versus Lapararoscopic or RObotic cystectomy). Trials 2016;17:35.

28. Parekh DJ, Reis IM, Castle EP, et al. Robot-assisted radical cystectomy versus open radical cystectomy in patients with bladder cancer (RAZOR): An open-label, randomised, phase 3, non-inferiority trial. Lancet 2018;391:2525-2536.

29. Boström PJ, Kössi J, Laato M, Nurmi M. Risk factors for mortality and morbidity related to radical cystectomy. BJU Int 2009;103:191-196.

30. Nieuwenhuijzen JA, de Vries RR, Bex A, et al. Urinary diversions after cystectomy: The association of clinical factors, complications and functional results of four different diversions. Eur Urol 2008;53:834-842.

\section{Address correspondence to: Rafael Sanchez-Salas, MD Department of Urology Institut Mutualiste Montsouris \\ Université Paris-Descartes 42 Boulevard Jourdan Paris 75014 \\ France}

E-mail: rafael.sanchez-salas@imm.fr

$\begin{aligned} & \quad \text { Abbreviations Used } \\ & \mathrm{ACCI}=\text { age-adjusted Charlson's comorbidity index } \\ & \mathrm{ASA}=\text { American Society of Anesthesiologists } \\ & \mathrm{BCa}=\text { bladder cancer } \\ & \mathrm{BMI}=\text { body mass index } \\ & \mathrm{CDC}=\text { Clavien-Dindo Classification } \\ & \mathrm{CI}=\text { confidence interval } \\ & \mathrm{CIS}=\text { carcinoma } \text { in situ } \\ & \mathrm{EBL}=\text { estimated blood loss } \\ & \mathrm{LRC}=\text { laparoscopic radical cystectomy } \\ & \mathrm{MIBC}=\text { muscle invasive bladder cancer } \\ & \mathrm{NAC}=\text { neoadjuvant chemotherapy } \\ & \mathrm{NMIBC}=\text { nonmuscle invasive bladder cancer } \\ & \mathrm{OR}=\text { odds ratio } \\ & \mathrm{ORC}=\text { open radical cystectomy } \\ & \mathrm{PLND}=\text { pelvic lymph node dissection } \\ & \mathrm{RC}=\text { radical cystectomy } \\ & \mathrm{RRC}=\text { robotic radical cystectomy }\end{aligned}$

